\title{
CRM Development on Mobile Application for SMEs in the Three Southern Border Provinces
}

\author{
Nimarunee Hayeewangoh ${ }^{1}$, Nattee Kachornkittiya ${ }^{2}$, Graitapon Termwitkachorn ${ }^{3}$ \\ ${ }^{1,2}$ Faculty of Management Sciences, Yala Rajabhat University, \\ ${ }^{3}$ Academic Resources and Information Technology Center, Yala Rajabhat University \\ ${ }^{1}$ nimarunee.h@yru.ac.th, ${ }^{2}$ nattee.k@yru.ac.th, ${ }^{3}$ graitapon.t@yru.ac.th
}

\begin{abstract}
The purposes of this research are to analyze, design, develop, and evaluate the efficiency and effectiveness of the CRM system. This study is a developmental research. The sample group used in the research was 390 SMEs entrepreneurs. The tools are efficiency assessment and effectiveness assessment. The results of analysing, designing, and development found that the work process of the CRM system consists of 5 processes: Login System, Customer System, Trading Information, Deal Information, and Reports. Also, there were representatives of information related to the system, including employees and managers who are working in the subsystem within the large system. The main stakeholders were managers and employees while the secondary stakeholders were customers. The efficiency and effectiveness of the system were at a high level with a mean of 4.63 and 4.41 , respectively
\end{abstract}

Index Terms

Customer Relationship Management System, Mobile Application, Small and Medium Enterprises

Article Received: 10 August 2020, Revised: 25 October 2020, Accepted: 18 November 2020

\section{Introduction}

Small and medium enterprises constitute the foundations of the national economy. They also meet the needs of consumers and perceive consumers' behavior in a niche market. However, they are inadequate to carry out proactive marketing activities and cannot face with business competition. Due to the complexity of consumers' behavior, this leads to the lack of behavioral data which can lead to strategic planning for a competitive advantage. However, nowadays, the internet technology has made advancement in SMEs to allow broad channels in contacting and contacting customers directly without any restrictions on location and time. Therefore, it allows customers to directly exploit the resources they demand. The marketing processes adopt the capabilities of internet technology that focus on customer relationship management in order to analyze the strategy, increase number of customers, maintain customers, build customer loyalty, and make potential profits [1]. Customer relationship management system, which is being called CRM system, represent a system that supports and strengthens customer relationship. It is able to display sales data, contact information, customer data collection, and an analysis of customer behavior for establishing plans or formulating strategies and creating values. It can also specify the status of the customers as well as maintaining customers and building customers to be loyal to the brand. In addition, the CRM system can support businesses succeed. As mentioned by [2], they proposed that businesses that can deploy CRM as part of a marketing strategy will grow faster than any other business. Moreover, CRM is recognized as a key strategy for small and large businesses especially businesses in SMEs who need to adopt CRM for excellent strategies as well as to increase competitiveness with other vendors. CRM is also in line with the belief that developing a lasting relationship with customers is the cornerstone for gaining customers' loyalty and for more profitable products and services [3]. It also enhances customers' services to be more efficient [4], which are 15,774 SMEs in the three southern border provinces [5] that are currently doing business.

At the same time, some businesses lose and disappear from the system as they continue to use traditional marketing systems. Therefore, the implementation of CRM system in SMEs is more suitable for the context of the three southern border provinces, rather than purchasing an information system to manage customer relationships and the management process required by SMEs in the area, as well as losing a lot of budget. It overcomes unskilled problems and enhances the potential of personnel in utilizing the system.

Therefore, the researchers recognize and attache great importance to the development of the fundamental economy that will affect the economic development in the three southern border provinces and the development of the nation as a whole through the capabilities of the electronic CRM system on the mobile application in order to promote small and medium enterprises to possess competitive potential. The relationship with customers can be engaged in anywhere and anytime which is appropriate to the context of the business. Analyzing and designing systems, developing, evaluating efficiency and evaluating the effectiveness of the system are also established.

CRM system represents a technology-based comprehensive approach to business processes which integrates customer information, sales, marketing and services. It also develops competitiveness by using internal resources such as technology, people, and customer relationship management processes to improve business efficiency. [6]; [7]; [8] and [9] suggested that the earlier idea had to be more than just a tool, but a deeply ingrained management strategy which will help overcome business competitors. In addition, [10] identified the CRM system as a business strategy, process, culture and technology which can add values through 
understanding and responding to the needs of customers individually. The successful CRM application requires the balanced integration of technology, processes and people. In terms of an evaluation of information system product performance, academicians have evaluated regarding to objectives and synthesized the scores of experts' opinions of individually by collecting data with the accuracy of information, information integrity, corrective operation of the system, quality of information, benefits received from information and ease of use [11]; [12].

Moreover, it was evaluated based on user satisfaction, which demonstrated the relationship between users and the information system as well as their interactions and increased quality of work [13]. Besides, the information systems performance assessment is the evaluation of a process to disclose system requirements, investigate designing and programming errors for determining their integrity, software security and software quality. The suitability of the product with the requirements consists of three techniques [14] which are for evaluating primary functions and checking for errors, including on-demand system, performance testing, ease of use test, and security tests by considering the input and display parts only. Furthermore [15] [16] proposed methods for assessing the effectiveness of CRM systems by observing users' experiences and the impact of use. It provides entrepreneurs information on their consumption experiences and assists them manage the effective customer relationships, including satisfaction assessments, customer retention assessment, such as measuring customer retention, repeating purchasing measurements [17], and assess customer loyalty. It is an assessment of the deep commitment that customers have with the business, a particular brand of products and services. It is a behavioral stability that is emphasized by true internal loyalty or a feeling of appreciation [18]. Moreover, the benefit that organizations will gain from customer loyalty is the increased profitability of their customers and creating values for customers [19].

\section{Research Objectives}

The purposes of this study are to 1) analyse and design the system; 2) develop the system; 3 ) evaluate the system efficiency; and 4) assess the system effectiveness.

\section{Research Methods}

\section{A. Research Design}

This research is conducted and developed by collecting qualitative data from entrepreneurs and analysing the information and designing the system. After the system is developed, the quantitative data were collected by evaluating the efficiency of the system from experts in information technology and experts in customer relationship management. The system was assessed the effectiveness from 390 participants and analyzed the data using descriptive statistics.

\section{B. Research Process}

Research process of this research has developed into 6 steps were shown in Fig. 1.

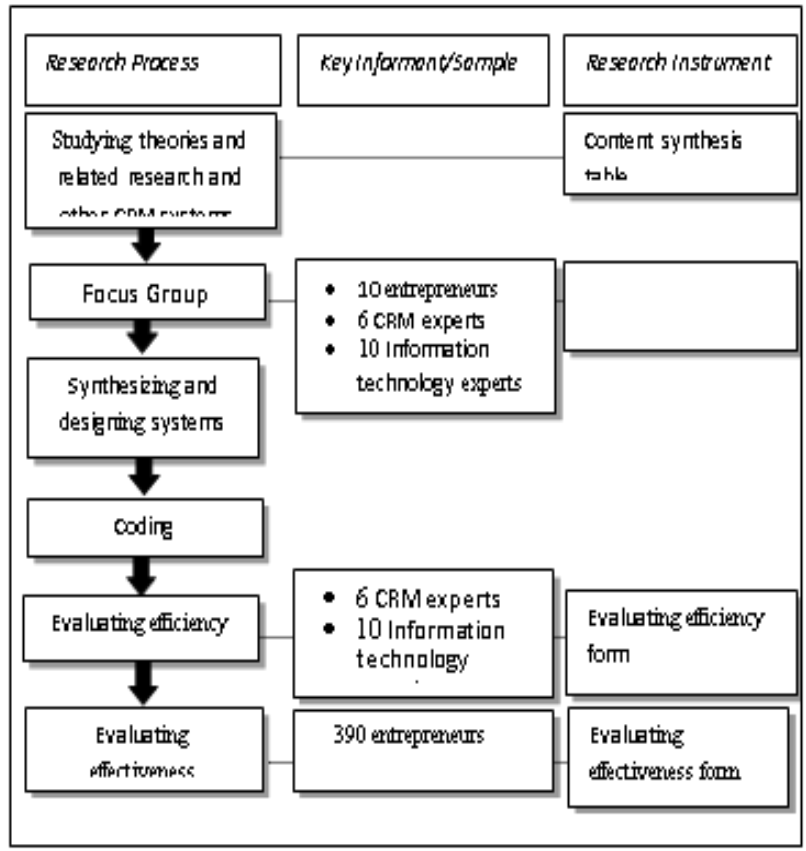

Fig. 1. PROCESS CRM Development on Mobile Application for SMEs in the Three Southern Border Provinces

\section{Results}

The results of this research will be presented as follows;

A: Results of the analysis and design of the system

$\mathrm{B}$ : Results of the development of the system

C: Results of the evaluation of the system efficiency

D: Results of the assessment of the system effectivness

A. Results of the analysis and design of the

B. system are presented through context diagram in

Figure 2.

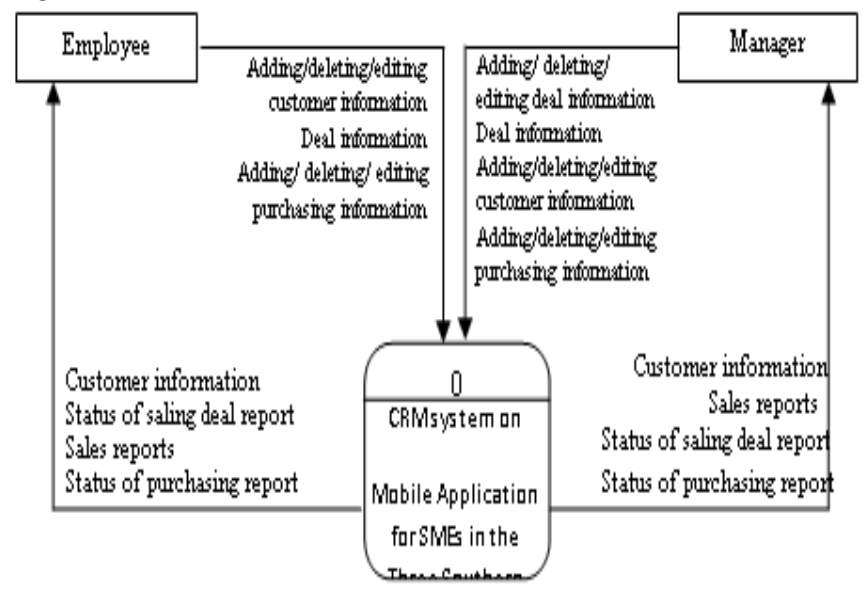

Fig.2 Context Diagram

Context diagram of the mobile application CRM system for SMEs in the three southern border provinces revealed the process symbol represented the work in every step of the system by the external agents related to the system, namely employees and managers, whose input and output data between the agent and the system can be described as follows. 
Table 1-1 External Agen

\begin{tabular}{|c|c|}
\hline Manager & Employees \\
\hline $\begin{array}{l}\text { Manager } \\
\text { adds/deletes/ edits } \\
\text { customer information } \\
\text { The system } \\
\text { reports customer } \\
\text { information to the } \\
\text { manager } \\
\text { - The manager } \\
\text { submits adding/ } \\
\text { deleting/ editing to the } \\
\text { system } \\
\text { displays the details of } \\
\text { deal The sysyem } \\
\text { - The system } \\
\text { reports deal situation } \\
\text { and sales } \\
\text { - The employee } \\
\text { adds/deletes/ edits } \\
\text { purchasing information } \\
\text { The system } \\
\text { reports purchasing } \\
\text { information }\end{array}$ & $\begin{array}{l}\text { - Employee } \\
\text { adds/deletes/ edits } \\
\text { customer information } \\
\text { - The system } \\
\text { reports customer } \\
\text { information to the } \\
\text { employee. } \\
\text { - Employee } \\
\text { requested for displaying } \\
\text { deal information } \\
\text { - The sysyem } \\
\text { displays the details of } \\
\text { deal The system } \\
\text { - } \\
\text { reports deal situation and } \\
\text { sales The employee } \\
\text { - } \quad \text { Tdds/deletes/ edits } \\
\text { purchasing information } \\
\text { - The system } \\
\text { reports purchasing } \\
\text { information }\end{array}$ \\
\hline
\end{tabular}

B. Results of the development of the system

The system that the researchers have developed includes the main menu: Customer Information, Deals, Orders, Payments, and Deal

Efficiency. In the work of the entrepreneurs, they can offer deals to repeat customers listed in the database and seek for new ones. To offer the customer a deal, the entrepreneurs can set the deal amount, price, and deal type through the deal code by forwarding information through the customer specified channel. When the customer accepts the deal, the system will promptly notify the entrepreneurs and will change the status from the prospective customer to be a customer interested in a product or service.

When a customer decides to accept the deal and make a payment, the system will transform the status of interested customers to repeat customers. While changing the status to a repeat customer, they can connect their connections to the system. When the information in the system changes, the information on the main page will be displayed to the entrepreneurs and the system will present the efficiency of the deal to the entrepreneurs to present the value of each deal. Simultaneously, the system can offer 7 days, 1 month, 3 months and 1 year historical data as well as offer history of deal, various deals and special offers. It enables entrepreneurs to use information to formulate marketing strategies which present an example of the system as in figure 3 . It can be observed that it is a compact system that provides functionality as needed based on the nature of the customer relationship.

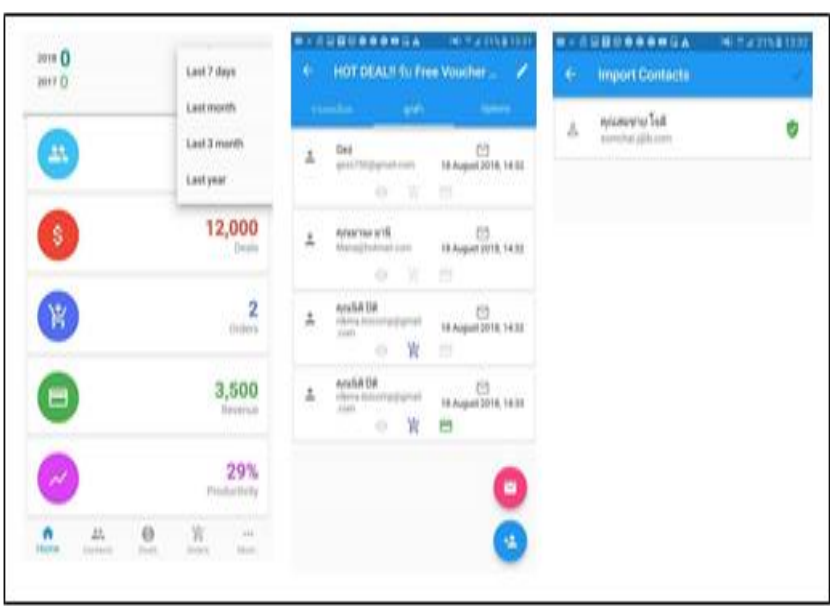

Fig.3 Example of CRM system on mobile application

C. Results of the evaluation of the system efficiency and results of the assessment of the system effectiveness will be presented in table 1.2

Table 1.2 The system efficiency and effectiveness

\begin{tabular}{|l|l|l|l|}
\hline Evaluation Lists & \multicolumn{2}{|l|}{ Evaluation } & Meaning \\
\cline { 2 - 4 } & $\begin{array}{l}\text { Mean } \\
(\bar{x})\end{array}$ & $\begin{array}{l}\text { Standard } \\
\text { Deviatio } \\
\text { n (S.D) }\end{array}$ & \\
\hline Efficiency & $\mathbf{4 . 6 3}$ & $\mathbf{. 4 9 0}$ & High \\
\hline $\begin{array}{l}\text { 1. The accuracy } \\
\text { of function } \\
\text { requirements }\end{array}$ & 4.31 & .514 & High \\
\hline $\begin{array}{l}\text { 2. The results } \\
\text { obtained from } \\
\text { the system }\end{array}$ & 4.05 & .480 & High \\
\hline $\begin{array}{l}\text { 3. The e ase of } \\
\text { use }\end{array}$ & 4.56 & .498 & High \\
\hline 4. The security & 4.24 & .460 & High \\
\hline $\begin{array}{l}\text { 5. The ability to } \\
\text { work }\end{array}$ & $4.68^{*}$ & $\mathbf{. 6 0 6}$ & Highest \\
\hline Effectiveness & $\mathbf{4 . 4 1}$ & .579 & High \\
\hline $\begin{array}{l}\text { 1. The } \\
\text { satisfaction of } \\
\text { the system }\end{array}$ & $4.42^{*}$ & .545 & High \\
\hline $\begin{array}{l}\text { 2. The customer } \\
\text { retention }\end{array}$ & 4.39 & .693 & High \\
\hline $\begin{array}{l}\text { 3. The customer } \\
\text { loyalty }\end{array}$ & $4.42^{*}$ & High \\
\hline
\end{tabular}

* Refers to the highest mean of the system efficiency and effectiveness

From Table 1.2, when experts assessed the efficiency of the system, it was found that the overall CRM system had a high level $=4.36, \mathrm{SD}=.490$ ). In the ability to work aspect, efficiency was the highest level $(=4.68, \mathrm{SD}=.460)$ because the system was able to process results and responds instantly to the users. After that, the system was applied for SMEs entrepreneurs in the three southern border provinces for a while. The entrepreneurs, then, evaluated the effectiveness. The results found the overall effectiveness of the CRM system was at a high level. $(=4.41, \mathrm{SD}=.606)$. The entrepreneurs' satisfaction of the system aspect was at a high level. $(=4.42, \mathrm{SD}=.579)$. The customer loyalty of the system was at a high level $(=4.42, \mathrm{SD}=.693)$. 


\section{Discussion and Conclusion}

The CRM system has been developed from analysing and designing, developing, and evaluating the efficiency. It is then introduced to entrepreneurs for their use. The system is also evaluated its effectiveness. The efficiency evaluation is at a high level because the system can respond to users and connect to external sources very quickly. It has been employed in the event of a vast number of users; however, the system remains stable. [20] claimed that the automated CRM system will help improve the functionality of the establishing process and updating customer information from 17 minutes to 2.3 minutes, which confirms the CRM system is good for employing. Plus, it has a faster response and processing. Moreover, it is detected that the CRM system was also extremely effective. This shows that the CRM system can manage customer relationships in a customer-centric manner. As [21] noted that customers remain critical and valuable assets to the organization. Besides, the CRM system also focuses on managing proposals that are suitable for customers who are enable customers to get more proposals according to their own interests and enable entrepreneurs to develop products and services that meet the expectations of the customers [22].

\section{Recommendations}

In this research, the researchers focus on developing systems for entrepreneurs to engage the relationships with customers. Therefore, in the future, additional modules for customers should be developed and focused on making decisions on the big data

\section{References}

[1] C. Kulsuwan, A.Pongklee, A. Issarapaibool. (2556). Effects of internet customer relationship management on customer loyalty of cosmetics business in Thailand. Journal of humanities and social sciences. 36 (6) November - December 2016.

[2] U.Ata \& A.Toker (2012). The effect of customer relationship management adoption in business-to-business markets. Journal of business \& Industrial marketing, 27(6), 197-507.

[3] G. Downling. (2002). Customer relationship management : In b2cmarket, often less is more. California management review, 44(3), 87-104.

[4] H.M. Beheshti. (2004). The impact of IT on SME in the United States. Information management \& computer security. 12(4): 318-327.
[5] Office of small and medium enterprises Promotion. (2017). Status of SMEs in Thailand on Economic, Society, and Culture. From www.Sme.go.th

[6] W.Tie. (2003). Implementing $\mathrm{crm}$ in SMEs: An exploratory study on the viability of using the ASP model. Swedish school of economics and business administration. Retrieved June 3, 2016 From www.citeseerx.ist.psu.edu

[7] N.A.Morgan, D.W. Vorhies, \& C.H. Mason. (2009). Market orientation, marketing capabilities and firm performance. Strategic management journal. 30(8), 909 -920.

[8] A. A. Mohammed \& B.B. Rashid (2012). Customer relationship management $(\mathrm{crm})$ in hotel industry: a framework proposal on the relationship among crm dimensions, marketing capabilities and hotel performance. International review of Management and Marketing. 2(4), 220230.

[9] I. J.Chen \& K. Popovich. (2003). Understanding customer relationship management (CRM): People processes and technology. Business process management journal, 9(5), 672-688.

[10] J. Reynolds. (2002). A practical guide to crm. New York: CMP Books.

[11] W. Laurie, (2006). Blacbox testing tutorial. [online]. Retrieved June 15, 2017 From www.agile.csc. ncsu.edu/sematerials/blackbox.pdf

[12] Delone, W. H., \& McLean, E.R. (2003). The DeLone and McLean model of information systems success: A ten-year update. Journal of management information systems, 19(4), 9-30.

[13] Balaban, G. P.N. (2009). Methodological approaches to evaluation of information system functionality performances and importance of successfulness factors analysis. Retrieved July 1, 2016 From www.ef.uns.ac.rs

[14] Khan, M. E., \& Khan, F. (2012). A comparative sudy of white box, black box and grey box testing techniques. 
InternationaljJournal of advanced computer science and applications, 3(6). Retrieved June 15, 2018 From www.citeseerx.ist.psu.edu/

[15] Johnson, M. D. \& Gustafsson A. (2000), Improving Customer Satisfaction, Loyalty and Profit, Jossey-Bass

[16] Minami, M. \& Dawson, J. (2007). The CRM Process in retail and service sector firms in Japan: Loyalty development and financial return. Michigan: Bay Port

[17] Aspinall, E., Nancarrow, C., \& Stone, M. (2001). The meaning and measurement of customer retention. Journal of Targeting, Measurement and analysis for Marketing, 10(1).

[18] P, Somwong., L, Soontorn. (2008). CRM Game to Win Customers' Satisfaction: Second Editon. Bangkok: UBCL Books Co.,Ltd

[19] Sin, L.Y.M., Tse A.C.B., \& Yim F.H.K. (2005). Crm:conceptualization and scale development. European journal of marketing, 39(11). Retrieved on June 26, 2016 From www.researchgate.net

[20] Haile, A. S. (2011). Automation of test cases for web applications automation of crm test cases. applied sciences bachelor of engineering information technology, Helsinki Metropolia University. Retrieved June 13, 2018 from www. theseus.fi /bitstream/handle/10024/57876/Alazar_BE ng_Thesis.pdf? sequence $=1$

[21] Wang et al. (2010) Wang, I. C., Huang, C. Y., et al. (2010). The influence of customer relationship management process on management performance. International Journal of Organization Innovation, 2(3), 40-50.

[22] Dyche, J. (2002). The CRM handbook: a business guide to customer relationship management. Addison-Wesley Professional 